\title{
Comparative Study on the Trans-Province Transfer of the Multiple Trauma Patients after Sichuan Earthquake
}

\author{
Guodong Liu"1\#, Shan Ou"\#, Jun Qiü", Danfeng Yuan³, Zhihuan Yang3, Zongke Zhou4, \\ Yuan Yao5, Suxing Wang', Xiuzhu Zhang3, Wuchao Wang', Dawei Liu ${ }^{3}$, \\ Zhengguo Wang', Jihong Zhou ${ }^{3 *}$ \\ ${ }^{1}$ Department 8, Research Institute of Surgery, Daping Hospital, Third Military Medical University, Chongqing, \\ China \\ ${ }^{2}$ Department of Anesthesiology, Chengdu First People's Hospital, Chengdu, China \\ ${ }^{3}$ State Key Laboratory of Trauma, Burns and Combined Injury, Research Institute for Traffic Medicine, Research \\ Institute of Surgery, Daping Hospital, Third Military Medical University, Chongqing, China \\ ${ }^{4}$ Department of Orthopedics, West China Hospital of Sichuan University, Chengdu, China \\ ${ }^{5}$ Department of Emergency Center for Traffic Injury, No. 117th Hospital of PLA, Hangzhou, China \\ Email: traumazjh@126.com
}

Received 3 January 2016; accepted 12 February 2016; published 15 February 2016

Copyright (C) 2016 by authors and Scientific Research Publishing Inc.

This work is licensed under the Creative Commons Attribution International License (CC BY).

http://creativecommons.org/licenses/by/4.0/

(c) (i) Open Access

\section{Abstract}

Background: Trans-province transfer of the patients has been successfully carried out and has greatly relieved the burden of the hospitals in Sichuan Province after Sichuan earthquake. The aim of the study was to retrospectively analyze the efficacy and feasibility of the trans-province transfer of the multiple trauma patients after Sichuan earthquake. Methods: A retrospective and descriptive analysis was conducted based on the medical records of the multiple trauma patients (ISS $\geq 16$ ) transferred to the Grade 3A hospitals outside Sichuan province. The patients were divided into two groups based on the distance to Sichuan province, i.e., Group A (the seismic patients transferred to Chongqing) and Group B (the seismic patients transferred to the other provinces/ municipalities). A comparison was done in aspects of distance of transfer, time from injury to transfer, vital signs, the infection rates (at transfer and on discharge), injury severity and prognostic indices (cure rate, disability rate and mortality). Results: The distance between Chengdu and the other places was at a wide range of $313-1653 \mathrm{~km}$, whereas the time from injury to transfer showed no statistical difference between groups $(P>0.05)$. There were no significant differences between both groups with respects to patient demographics, injury mechanism, time from

\footnotetext{
*Corresponding author.

${ }^{\#}$ These authors contributed equally to the study.

How to cite this paper: Liu, G.D., Ou, S., Qiu, J., Yuan, D.F., Yang, Z.H., Zhou, Z.K., Yao, Y., Wang, S.X., Zhang, X.Z., Wang, W.C., Liu, D.W., Wang, Z.G. and Zhou, J.H. (2016) Comparative Study on the Trans-Province Transfer of the Multiple Trauma Patients after Sichuan Earthquake. Open Journal of Earthquake Research, 5, 7-19.
} 
injury to transfer, vital signs, infection rate and injury severity. The prognostic indices showed no significant difference, except for FIM scores $(P<0.05)$. Conclusions: The results of the study indicate that the different distance of the transfer of the multiple trauma patients does not aggravate the severity or deteriorate the prognosis, which proves that the medical supportive transfer system is acceptable, effective and worthy of further implementation in China, which may be ascribed to the advanced transportation system and high level of therapeutic capacity of the hospitals. In the meantime, attention should be paid to psychological intervention and functional rehabilitation during the treatment of the transferred seismic patients.

\section{Keywords}

\section{Earthquake, Hospital Transfer, Vital Signs, Injury Severity Score, Prognosis}

\section{Introduction}

An earthquake measuring 8.0 on the Richter scale occurred at 14:28 p.m. on May 12th, 2008 in Sichuan province, China. Tremors were felt as far away as Beijing and even Hong Kong [1]. The epicenter was located in Wenchuan (population 111,800), $90 \mathrm{~km}$ northwest of Chengdu, the provincial capital of Sichuan province. This was considered to be the deadliest earthquake since the 1976 Tangshan earthquake in China, even the most severe natural disaster of the 21st century to date [1] [2]. Until June 12th, 2008, Sichuan earthquake had led to 69,159 deaths, 17,469 missing, 374,141 wounded and 95,516 hospitalizations [3].

The earthquake destructed the main traffic lines (including roads, highways, bridges and railways) [4], the lifelines (including water, gas, electricity) and severely damaged many hospitals [1] [5] [6]. This destructive earthquake has created a situation beyond the emergency response capacity of the local facilities and severely hampered a prompt and timely system response [7] [8], which contributed to a nationwide ever first large scale trans-province transfer of the seismic patients.

The collection and interpretation of earthquake injury data [9] provide relevant information for clinicians, institutions, and governments on issues related to the population's health and injury sustained in an earthquake and hence cater for reference for medical aid in the future similar events. In fact, clinical research under disaster situations was difficult in face of the ensuing chaos and often incomplete medical record keeping [10] [11]. Most of the studies related to earthquake have dealt with emergency medical and rescue systems, as well as medical support, first aid, nursing care [12]-[15] during the course of the transfer of the seismic patients [12]. There has not been reported the precise analysis of the efficacy, safety and feasibility of the transfer of the patients to the hospitals outside Sichuan province after earthquakes. With this requirement, we have made our efforts and spent over a year to collect the medical data of 3145 seismic patients who were transferred to 91 hospitals nationwide outside Sichuan province. The patients have been transferred to different grade hospitals including the Grade 3A hospitals (rated as the highest level hospital in China) with aim to obtain the optimal treatment. As the neighbor of Sichuan province, Chongqing was considered the prioritized place to receive the transferred patients from the disaster area, for these two places were all along considered as one family (Chongqing was administratively divided from Sichuan province and set as municipality in 1997).

The aim of the study was to retrospectively analyze the efficacy and feasibility of the large-scale trans-province transfer of the seismic patients especially the multiple trauma patients after Sichuan earthquake.

\section{Materials and Methods}

\subsection{Data Collection}

A structured survey form was developed to collect medical records of the seismic patients transferred to the hospitals outside Sichuan province. The information collectors were trained before formal data collection. The whole course of data collection was under a strict quality control by quality control staff: after filling out one survey form, the quality control staff reviewed the survey in terms of form and content so as to verify whether the writing was clear and whether there were missing items or logic errors. One survey form was not accom- 
plished until the quality control staff finished the inspection and the team leader signed his name for confirmation. All the data were input into the Trauma Database System V3.0 [14] by special personnel. The items included distance between Chengdu and the back-up hospitals, time of transfer, general personal information (gender, age, occupation), cause of injury, injury time and site, injury causes and mechanism, injury location of the body, activity at injury, vital signs, trauma score, examinations, drug use, operation, terminal diagnosis, infections, outcomes, etc. The survey was carried out from December 2009 to September 2010, by five board certified members. After obtaining approval from each hospital administrative office, we arranged on-site visits to review the specified medical records [5] [16]. Confidentiality of the patient information was maintained by deidentifying all data and by limiting access to the computer database to the investigators. The study proposal was approved by the Ethics Committee of Third Military Medical University.

\subsection{Study Design}

Inclusion criteria: 1) the patients who were damaged directly and indirectly by Sichuan earthquake; 2) ISS $\geq 16$; 3) hospitalized in the Grade 3A hospitals that received the transferred patients. Exclusion criteria: the patients in the hospitals below Grade 3A and those with non-injury diseases such as delivery and internal diseases.

The study divided the hospitals into two groups, the Group A involved the patients transferred to Chongqing and the Group B involved the patients transferred to the hospitals outside Chongqing and Sichuan province.

\subsection{Parameters for Analysis}

The parameters for comparative analysis included the distance between Chengdu and the back-up hospitals, the time from injury to transfer, the sex, the age \& age section, the pre- and post-transfer physiologic variables including systolic blood pressure (SBP), mean arterial pressure (MAP), heart rate (HR) and respiratory rate (RR), the injury mechanism, the infection on admission and discharge, the injury severity variables including injury severity score (ISS), new injury severity score (NISS) and Glasgow coma scale (GCS), the prognostic indices including length of hospital stay, cure rate, disability rate, mortality rate and functional index measure (FIM), etc..

\subsection{Data Analysis}

All the data were collected prospectively and input into the Trauma Database System V3.0. Statistical analysis was performed using Prism (Graph Pad Software, Inc., San Diego, CA, USA). For categorical data, analyses were conducted using the Chi-square test and odds ratios. For continuous variables, Student's $t$ test was performed. A $P$ value of $<0.05$ was considered as statistical difference.

\section{Results}

\subsection{General Information}

Based on the inclusion criteria, the study involved 131 inpatients in the Group A and 61 inpatients in the Group B. The patients were transferred from 12 identified places and 2 unclear places (Table 1). The distance between Chengdu and the places that accepted the transferred patients showed a wide range from $313 \mathrm{~km}$ (to Chongqing) to $1,653 \mathrm{~km}$ (to Shanghai). See Figure 1. As for the time from injury to transfer, there found no statistical difference between groups $(P=0.5079$, Figure 2 and Figure 3).

Comparisons between the two groups revealed no statistical differences with respects to the patient age or gender, with male to female ratio of 0.93:1 in the Group A and 0.65:1 in the Group B ( $P=0.2582$, Table 2$)$. The age of the inpatients was at a range of 0-88 years. The inpatients were divided into five age sections to investigate the distribution of the total multiple trauma patients and that in two groups. From angle of general age distribution of the inpatients, those at age $\geq 61$ years and $\leq 17$ years accounted for $65.63 \%$ of total (Figure 4). As for the age distribution in two different groups, the inpatients at age sections of $\geq 61$ years and $\leq 17$ years in the Groups A and B were larger than those at other age sections (Figure 5).

The major occupation of the injured patients was the peasant and student, which accounted for $30.53 \%$ and $27.48 \%$ respectively in the Group A, and $39.34 \%$ and $22.95 \%$ respectively in the Group B, with no statistical difference between groups $(P=0.2340$ for both). See Figure 6 . 


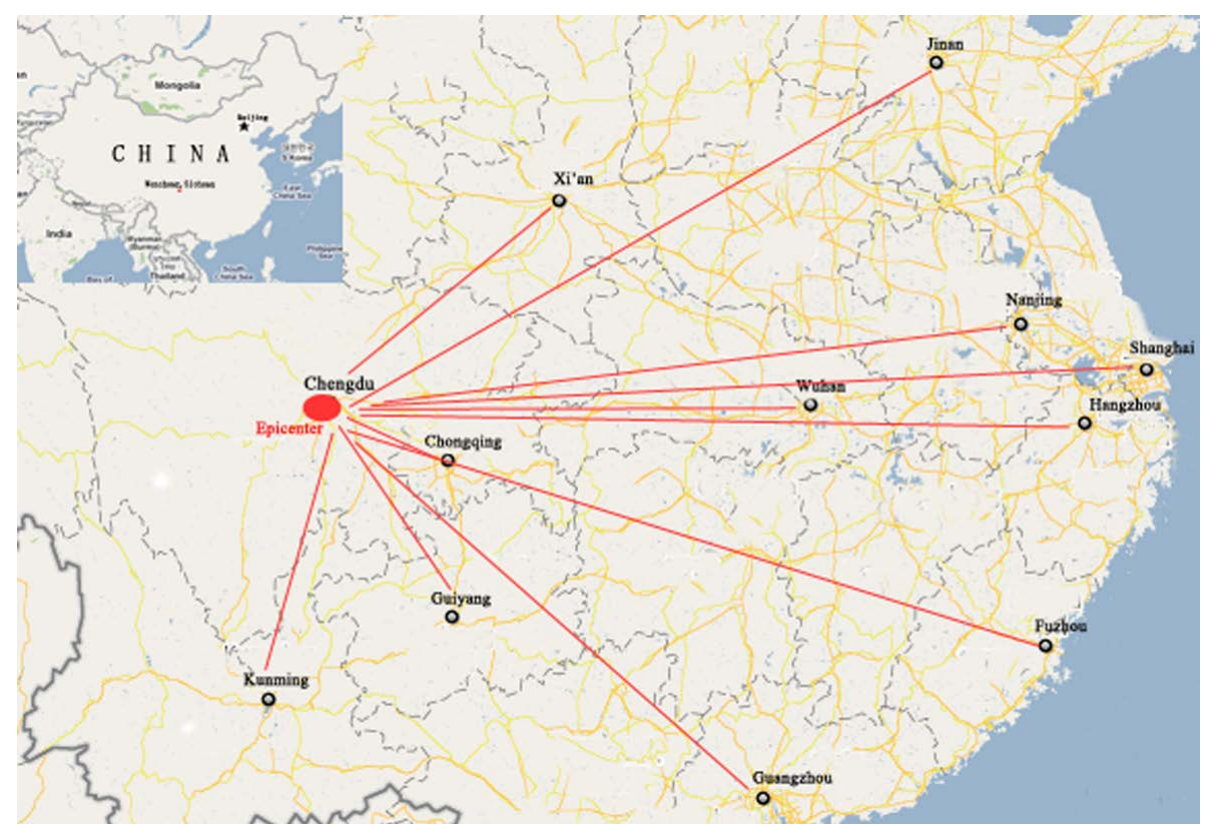

Figure 1. The map shows the distance between Chengdu and the other places (provincial capital name) that accepted the transferred patients (range, $313-1653 \mathrm{~km}$ ).

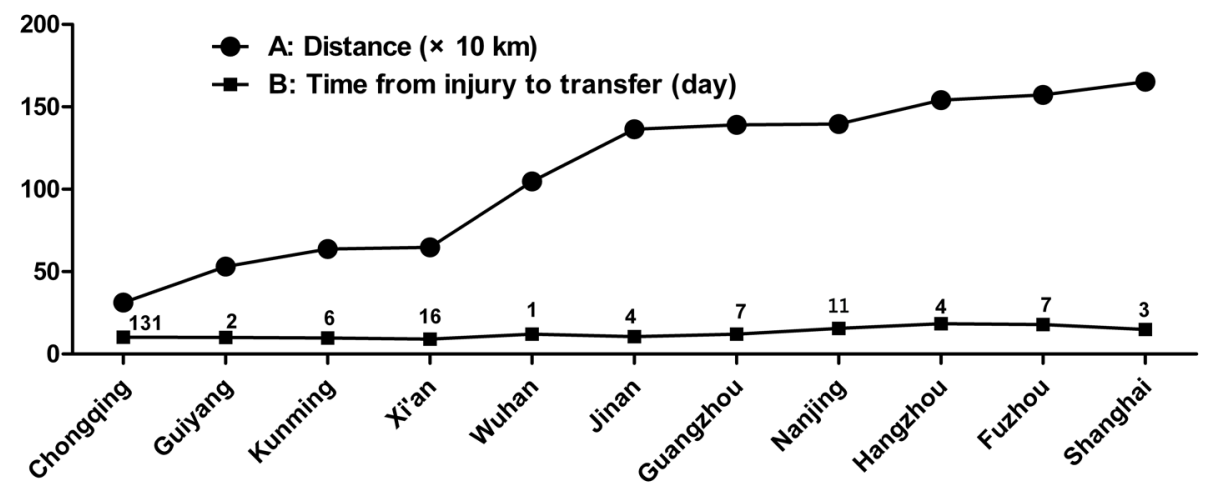

Figure 2. The diagram shows the distance between Chengdu and the other places as well as the time from injury to transfer. The numbers on the curve B stands for the number of the multiple trauma patients.

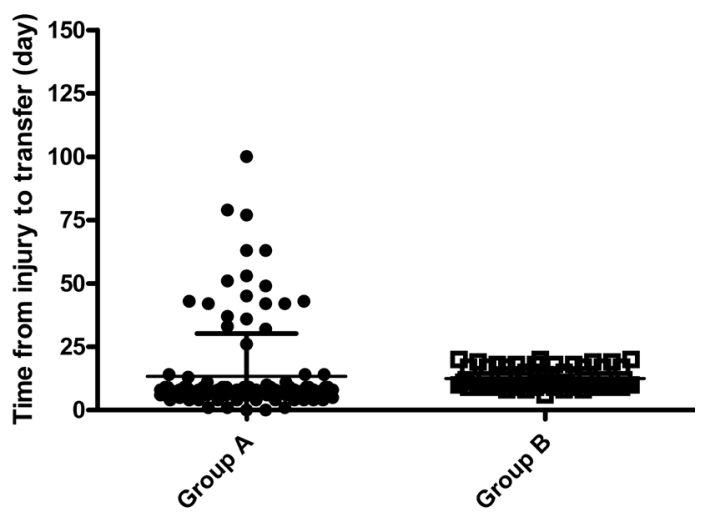

Figure 3. The scatter diagram shows the distribution of the time from injury to transfer in two groups. The data were expressed as mean \pm S.D.. The mean time was $11.54 \pm 11.04$ days in the Group A and $12.51 \pm 3.94$ days in the Group B $(P=0.5079)$. 


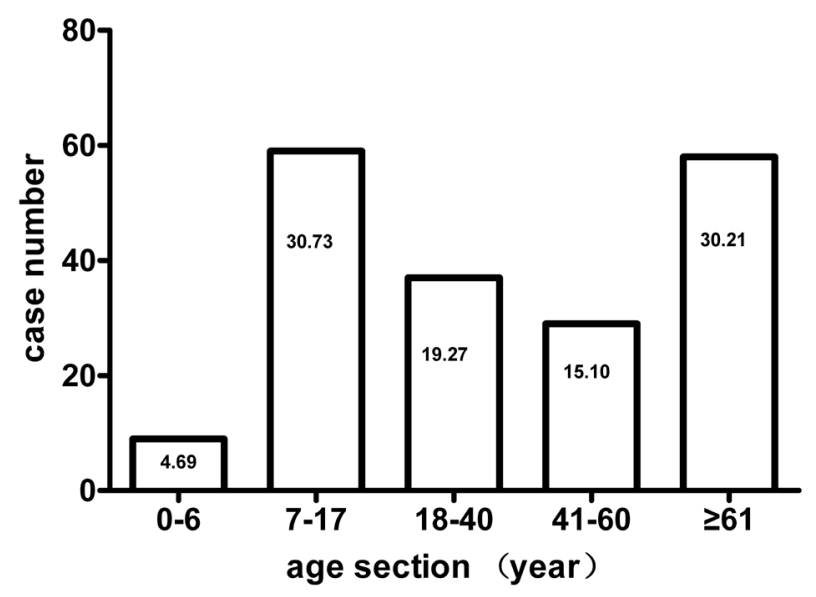

Figure 4. The general distribution of the inpatients of different age sections (within the hollow column was the percentage the age group accounted for).

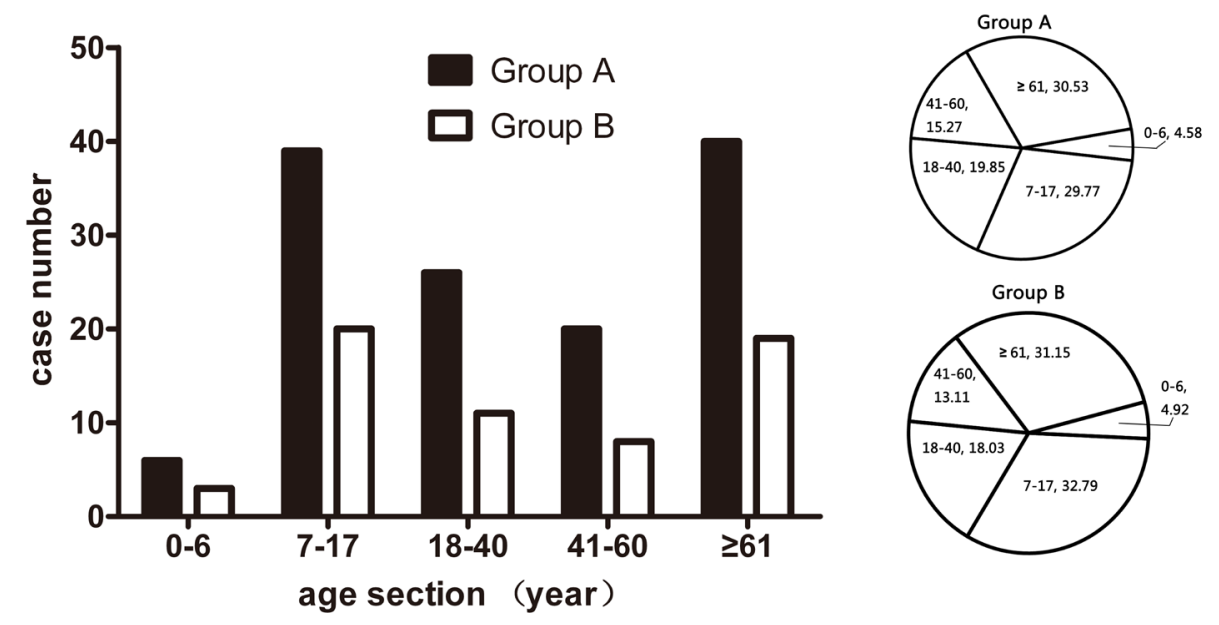

Figure 5. Distribution of the inpatients of different age sections in two groups.

Table 1. The information about the places and the patients transferred.

\begin{tabular}{ccc}
\hline Places & Cases & Percentage (\%) \\
\hline Beichuan County & 1042 & 33.13 \\
Mianzhu County & 399 & 12.69 \\
Anxian County & 355 & 11.29 \\
Pingwu County & 310 & 9.86 \\
Jiangyou City & 165 & 5.25 \\
Deyang City & 146 & 4.64 \\
Wenchuan County & 100 & 3.18 \\
Shifang City & 100 & 3.18 \\
Qingchuan County & 67 & 2.13 \\
Mianyang City & 65 & 2.07 \\
Pengzhou City & 39 & 1.24 \\
Youxian District & 29 & 0.92 \\
Unclear & 204 & 6.49 \\
Nonerecord & 124 & 3.94 \\
\hline
\end{tabular}


$\square$ Peasant Student Worker Resident $\square$ Businessman Other

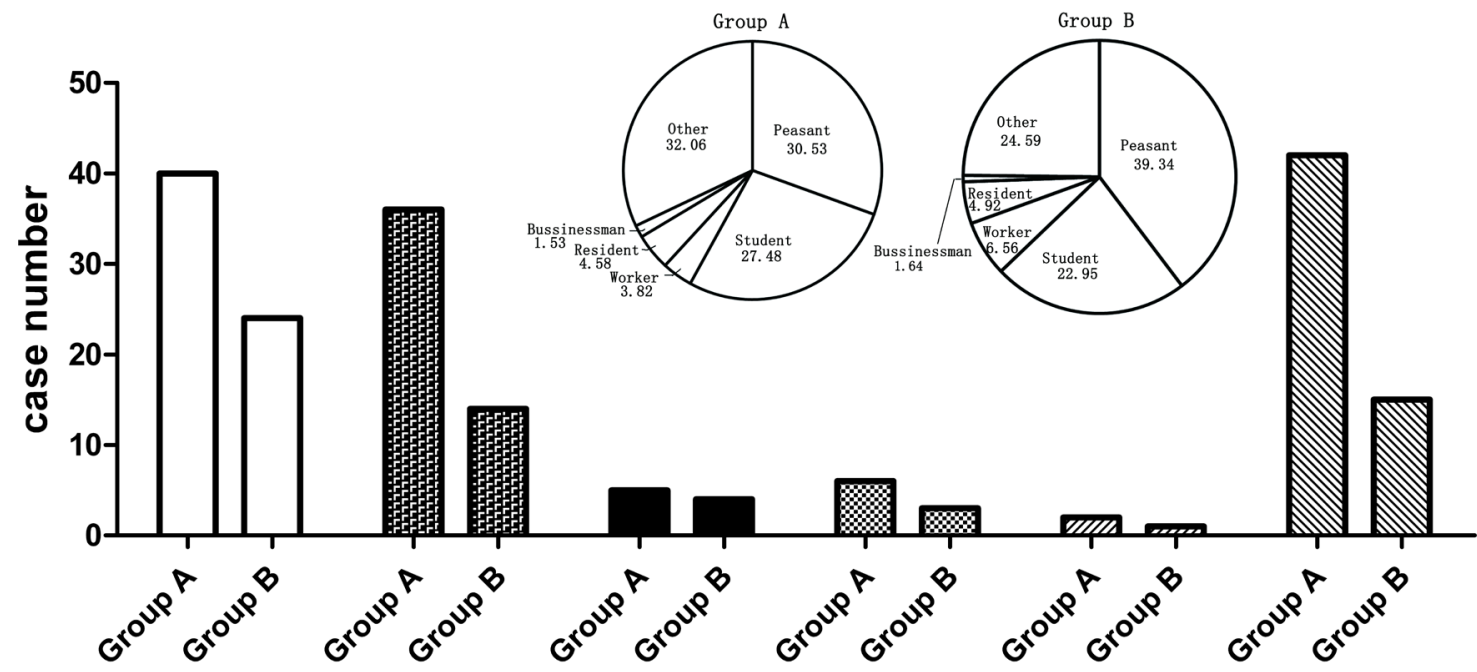

Figure 6. Distribution of the occupation. The major occupation of the injured patients was the peasant and student, which accounted for $30.53 \%$ and $27.48 \%$ respectively in the Group A, and $39.34 \%$ and $22.95 \%$ respectively in the Group B, with no statistical difference between groups $(P=0.2340$ for both). The pie charts represent the percentage of the occupation of different population.

Table 2. Demographic data and the time from injury to transfer in both groups.

\begin{tabular}{cccc}
\hline Items & Group A & Group B & $P$ Value \\
\hline Gender (Male/Female) & $63 / 68$ & $24 / 37$ & 0.2582 \\
Age (year) & $42.45 \pm 23.34$ & $46.84 \pm 23.93$ & 0.2302 \\
Time from injury to transfer (d) & $11.54 \pm 11.04$ & $12.51 \pm 3.94$ & 0.5079 \\
\hline
\end{tabular}

\subsection{Injury Severity and Physical Examination Results}

The proportion of the patients sustaining injuries due to blunt mechanisms was nearly identical in both Group A and Group B $(93.9 \%$ and $93.4 \%$, respectively, $P=0.8414)$. The other injury mechanisms included mainly ruin injury and laceration, which accounted for less than $7 \%$ in both groups. Infection rate on admission in the Group A and Group B was $22.90 \%$ and $9.84 \%$ respectively $(P=0.0308)$.

A comparison on ISS, NISS and GCS showed no statistical difference between two groups $(P>0.05$ for all). There found no statistical difference in aspects of the vital signs including SBP $(P=0.5646)$, MAP $(P=$ $0.1081)$, HR $(P=0.1232)$ and RR $(P=0.1947)$. The SBP $<90 \mathrm{mmHg}$ was found in 5 patients of the Group A and 2 of the Group B, with no statistical difference $(P=0.7105)$. See Table 3 and Figure 7.

\subsection{Prognostic Indices}

No death of the multiple trauma patients occurred in both groups. There showed no significant statistical difference in regard of the length of hospital stay, which was (40.45 \pm 20.22$)$ days in the Group A and (41.42 \pm 21.77$)$ days in the Group B $(P=0.8091)$. Similarly, no significant difference was found in the cure rate and disability rate (both $P=0.1535$ ). The infection rate was 0 in both groups. However, there was significant difference in FIM $(P=0.017)$. See Table 4 .

\section{Discussion}

The incidence of the large-scale natural disasters, for example, hurricane and earthquake, presents an ascending trend worldwide [17] [18]. In terms of human casualty, property damage and general public assets, the earthquakes are the most costly of natural disasters [10] [19]. The earthquake resulted in a large number of ca- 


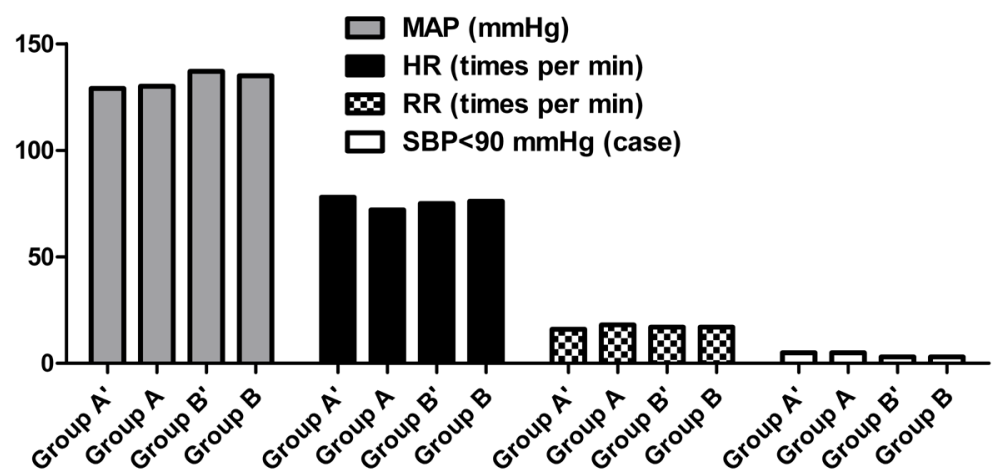

Figure 7. The comparison on the vital signs including MAP, HR, RR and SBP before transfer (Group A' and Group B') and after transfer.

Table 3. Comparison on injury severity and physical examination results.

\begin{tabular}{cccc}
\hline Items & Group A & Group B & $P$ Value \\
\hline ISS & $26.49 \pm 18.48$ & $23.03 \pm 13.07$ & 0.1903 \\
NISS & $29.94 \pm 17.82$ & $26.95 \pm 12.80$ & 0.2413 \\
GCS & $14.84 \pm 0.63$ & $14.92 \pm 0.28$ & 0.3606 \\
SBP (mmHg) & $120.18 \pm 20.60$ & $122.78 \pm 32.24$ & 0.5646 \\
MBP (mmHg) & $83.20 \pm 13.47$ & $87.03 \pm 18.72$ & 0.1081 \\
SBP $<$ 90 mmHg (case) & $5(3.82 \%)$ & $3(4.92 \%)$ & 0.7105 \\
HR (times/min) & $76.95 \pm 6.24$ & $78.54 \pm 7.39$ & 0.1232 \\
RR (times/min) & $16.34 \pm 3.21$ & $17.01 \pm 3.55$ & 0.1947 \\
\hline
\end{tabular}

Table 4. The prognostic indices in both groups.

\begin{tabular}{cccc}
\hline Items & Group A & Group B & $P$ Value \\
\hline Length of hospital stay (d) & $40.45 \pm 20.22$ & $41.42 \pm 21.77$ & 0.8091 \\
Infection rate (\%) & 0 & 0 & 0.1535 \\
Cure rate (\%) & 100 & 100 & 0.0172 \\
Disability (\%) & 28.2 & 0 & $11.38 \pm 0.56$ \\
Mortality (\%) & 0 & $11.04 \pm 1.05$ & 0.0 \\
FIM score &
\end{tabular}

sualties within a short time [20]-[23], which put forward a formidable challenge to medical systems which were immediately overwhelmed by the vast populations requiring healthcare [24] [25]. Therefore, the patients who could not receive the timely medical treatment and/or were just treated preliminarily needed transferring to the medical facilities outside the disaster area for a better treatment.

The transfer of the seismic patients played a vital role in improving the survival rate of the seismic patients. However, the transfer of the patients between hospitals still remained a challenging topic for us, as was based on a quick, scientific and accurate injury judgment. With the large number of the wounded in a very short span of time, the rescue foci did depend on not only the treatment capacity, but also the reasonable and effective transfer strategy. The treatment and transfer of the seismic patients usually consulted the methods treating the war wound, i.e., the echelon of care and the medical evacuation [26]-[28]. The pushing force for the massive transfer of the seismic patients was mainly due to a quick accumulation of the patients, especially the multiple trauma 
patients, in a very short span of time, which exceeded the medical rescue capacity of the local medical facilities. Meanwhile, with many strong aftershocks (30,235 aftershocks had been detected since May 12th, 2008) and the expansion of the search scope as well as the dam failure peril of the Tangjiashan quake lakes for the most (Figure 8) behind the blockages, the seismic patients from the hospitals in the coverage area of the quake lakes were ordered to be transferred as quickly as possible to the other hospitals in a relatively safe areas including the places outside Sichuan province. Some of the inpatients who received preliminary examination and medical aid (including infusion, fracture fixation, debridement, dressing, etc.) in the local hospitals must be transferred to other places or outside Sichuan province to facilitate the admission of the upcoming patients requiring urgent hospitalization. However, in consideration of the individual condition and human-based management, the transfer did not include the patients with following factors including decompensated shock, suspected intracranial hypertension of head injury, possible hernia, spinal cord injury with respiratory dysfunction, unstable injury after thoracic and abdominal injuries, life-threatening injuries as well as the disagreement of the wounded or their family members or relatives. In this study, the transfer of the seismic patient started from the very day after the earthquake and continued till 100 days after the earthquake (Figure 2). The mean time from injury to transfer was $(11.54 \pm 11.04)$ days in the Group A and (12.51 \pm 3.94$)$ days in the Group B, with no significant difference. The time coincided with the quake lake events (May 22nd, 2008). The patients involved in the study were transferred from the hospitals in different places, including Chengdu and the cities surrounding the quake lakes. All the hospitals included in this study are the general hospitals at Grade 3A and have sufficient capacity in treatment of the diseases including traumatic brain injury, serious multiple fractures, etc. The analysis on the general data of the inpatients in two groups manifested the successful overall treatment results of the medical institutions either in or outside Chongqing, indicating that the secondary transfer of the multiple trauma patients was successful and suited to China's national conditions.

As the quantitative criteria for evaluating the injury severity, trauma score has become the essential objective criteria to provide basis for improvement of the quality of the treatment and prediction of the probability of the patient survival during the pre-hospital emergency treatment, the hospital treatment and the ICU care [29]. This study involved three types of trauma score including ISS, NISS and GCS. The ISS was based upon the Abbreviated Injury Scale (AIS). The AIS was developed in 1969 to grade the severity of the individual injuries and ISS was the most widely used measure of injury severity in patients with trauma [30]. The patients in the study were rated as multiple traumas, with ISS $\geq 16$. NISS was a simple modification from ISS and thought to be better in predicting the functional outcomes in the survivors with musculoskeletal trauma [31]. GCS score on admission was an excellent criterion for surgery [32]. In the study, the ISS, NISS and GCS were $26.49 \pm 18.48$, $29.94 \pm 17.82$ and $14.84 \pm 0.63$ respectively in the Group A and $23.03 \pm 13.07,26.95 \pm 12.80$ and $14.92 \pm 0.28$ respectively in the Group B, with no statistical difference between groups (all $P>0.05$ ), indicating that the patients in two groups were comparable.

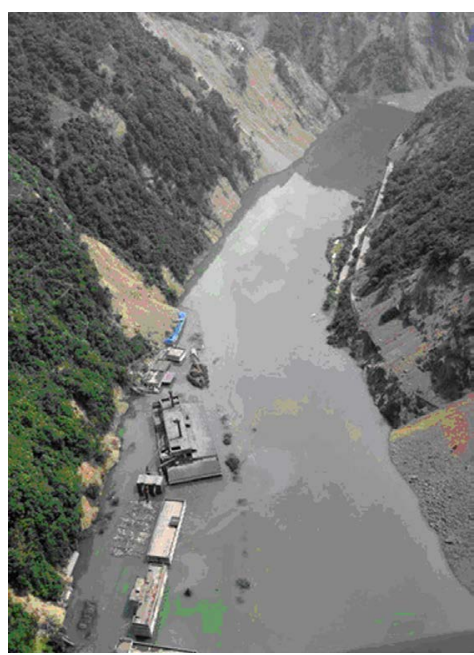

Figure 8. Photo shows an aerial view of quake lakes formed after earthquake in Beichuan County, Southwest China's Sichuan Province (taken on May 22nd, 2008). 
A quick as possible transfer of the patients to the hospitals was critical for the prognosis. The absence of rapid transit tool was bound to seriously affect the optimal medical care for the patients especially the multiple trauma patients. Under the overall arrangements depending on the specific circumstances, a multi-way and three-dimensional transport system involving the ambulances, the trains (onboard train), the aircrafts (either the military helicopters or the civilian aircrafts, most as the chartered) as well as other transportation tools like family cars were reasonably utilized to safely, effectively and quickly transfer the patients to the destination hospitals. The distance from the earthquake zone in the Group B was larger than that in the Group A (see Figure 1 and Figure 2). Under the premise of initial treatment (such as the transfusion on the way) of the wounded, the transfer did not aggravate the injury severity of the patients, with no significant changes of the vital signs (SBP, MAP, HR and $\mathrm{RR}$ ) before and after transfer. The number of the patients with shock (SBP $<90 \mathrm{mmHg}$ ) showed no increase either.

The students and the elderly with the earthquake injuries even deaths accounted for a high proportion. In this study, no significant difference was found in aspect of gender and age in both groups (both $P>0.05$ ). The age section results showed that the patients were concentrated in the patients at $\geq 61$ years and at below 17 years, accounting for $65.63 \%$. The patients at $\geq 61$ years and at below 17 years accounted for $64.88 \%$ in the Group A and for $68.86 \%$ in the Group B, which was in accordance with the general age section results. In the meantime, the results of the study consisted with the previous report of Chan et al. [1], in which $40 \%$ of patients were older than 60 years, with the median age of 79 years. The earthquake occurred at 2:30 p.m., which was exactly the school time for the primary and secondary schools in China and the students just gathered together in the classroom for preparation of the class [3]. While at that time, the pre-school children and the elderly were in a snap or about to get up after a nap. Both parts of the population were in non-open areas to be vulnerable to the burying caused by collapse of the buildings especially the "tofu-dregs schoolhouses" and the single storey farmhouses [24] when the earthquake broke out. The building had no uniform aseismatic standard in the vast rural areas and the urban fringes in China. At the same time, the local residents especially the elderly and the children were generally with low level of education on knowledge of disaster prevention and relief, which may be another reason for high proportion of the students and the elderly with the earthquake deaths and injuries. Furthermore, the earthquake zone was mountainous, which added difficulties to self-help and mutual aid of the elderly and the children [3]. The distribution of the occupation showed that the major occupation was focused on the peasants (33.33\%) and the students (26.04\%). The peasants and the students accounted for $30.53 \%$ and $27.48 \%$ respectively in the Group A, and $39.34 \%$ and $22.95 \%$ respectively in the Group B. Most of the peasants were the elderly, which was in accordance with the results of the age section. In the meantime, a large number of people of working age in rural China have migrated to urban settings for better job opportunities, leaving behind a population in which older people and children are overrepresented [1] [3].

Knowledge of the variation of mechanism of injuries, patterns and management of earthquake injuries may provide useful strategies for patient care and prevention of further complications. In this study, the blunt injury (mostly caused by the building collapse) was the main injury mechanism, accounting for $93.9 \%$ in the Group A and $93.4 \%$ in the Group B, which was in accordance with the earthquake damage [2] [17] [33]. The complicated geographic features made the access to the site a major issue and most of the severely injured have died in the scene within $24-48$ hours after earthquake, which may partially explain why both the hospital mortality $(1.69 \%)$ and the proportions (each $<10 \%$ ) of the life threatening traumas, such as chest trauma, abdomen trauma and brain trauma in the admitted victims were low [3] [34]. The study involved the secondary transfer of the wounded who had received an initial treatment prior to the transfer, which greatly reduced the difficulty of the medical care and provided basis for improvement of the prognosis (the mortality rate was zero in both groups) after the transfer. Part of the patients had infection on the time of transfer, with infection rate of $22.90 \%$ in the Group A and 9.84\% in the Group B. With hospital treatment after the second transfer, the infection rate on discharge was 0 , indicating a successful control of the infection in both groups.

The Sichuan earthquake resulted in many muscle compression injuries even crush syndrome (including compartment syndrome) that was the most prominent medical syndrome necessitating critical care [7] [35]-[37] after the injured were rescued from the debris. Unfortunately, some patients with severe crush syndrome must be managed with amputation, which led to disability and affected the future work and life [38]. In fact, the amputation can be avoided in part of the patients with severe crush syndrome according to the degree of the limb ischemia, with or without controllable renal dysfunction and other important organ injury. What the surgeons could do was to take appropriate treatment measures (including the timely transfer and the appropriate medical 
measures) to salvage the endangered body parts to minimize the possibility of the amputation [39] [40]. One of indices for evaluation of the prognosis was the disability that was $28.2 \%$ in the Group A and $18.0 \%$ in the Group $\mathrm{B}(P>0.05)$. In this study, the functional recovery differed in both groups, with FIM score for $11.04 \pm 1.05$ in the Group A and $11.38 \pm 0.56$ in the Group B $(P<0.05)$, which was not in consistency with the disability rate. The possible reason was that the patients admitted to the hospitals in Chongqing was far more than those in the other places (10 provinces/municipalities), when the great importance was attached to the basic therapy for the inpatients, with ignorance of the late functional training and rehabilitation.

For the adolescents or the students in major disasters, besides medical treatment of the physical trauma, the medical institutions have also begun to implement psychological interventions [18] to reduce the psychological trauma [41]-[44]. In this study, many of them ( $20 \%$ or so) lost their family members or relatives and they were accompanied by the volunteers or the others rather than their relatives during their hospital stay. The patients were accompanied by a psychiatrist or a volunteer during the course of the transfer, with early psychological intervention if possible, could substantially reduce the psychological fear of the wounded and their families, even some of the first responders [1] [45] [46], which guaranteed good compliance for the transfer and treatment as well as improvement of the prognosis [47]. The study paid attention to the psychological problems of the inpatients, but there regrettably recorded no related indices, for example the post-traumatic stress disorder (PTSD) [48]. Nevertheless, a precise evaluation and analysis (either long term or short term) of the psychological status of the seismic patients is worthy of further strengthening.

In this study, there showed no significant difference in the disability but significant difference in the FIM score, suggesting that we should pay attention not only to the basic vital signs and limb salvage, but also to postoperative functional training and rehabilitation in face of a similar situation in the future, as was the real aim of the best treatment. The psychological intervention was basically finished on the discharge of the patients but the psychological impact caused by the earthquake was not over all at once, which needs further follow-up study of the psychological intervention. The study gives a clear view on how to cope with future disasters with better experience.

Behind the success existed some thinking. Most peers have given top priority to saving the lives especially in the initial medical treatment and neglected the minor life-threatening injuries. This kind of emergency treatment may lead to neglect the control of the infection, as may be the cause for existence of the infection in the transferred patients. In addition, in face of the sudden earthquake, all the medical institutions in China were in panic for more or less in the medical treatment of the wounded and lacked systematic consideration on the medical rescue and the transfer of the patients, suggesting that to improve the emergency and treatment system [28] at all levels is imperative to minimize the casualties and take more effective treatment as possible before the disaster [49] [50]. The transfer involved in this study was safe and effective, but when looking back, the swarmed transfer was not the most economical way and the whole community lacked an integrated transfer system [51]. Under a condition with a large number of patients in a very short period of time, only by strengthening the organization of the treatment could an efficient and orderly medical treatment be made and the maximum curative effect with the minimum resources being obtained, as was what the earthquake left us for thinking and the problem to be solved.

\section{Conclusion}

The results of the study indicate that the different distance of the transfer of the multiple trauma patients does not aggravate the severity or deteriorate the prognosis, which proves that the medical supportive transfer system is acceptable, effective and worthy of further implementation in China, which may be ascribed to the advanced transportation system and high level of therapeutic capacity of the hospitals. In the meantime, great importance should be attached to psychological intervention and functional rehabilitation during the treatment of the transferred seismic patients.

\section{Limitations}

The study group has obtained all the data of the inpatients from hospitals in Chongqing and the data just from military hospitals in the other provinces/municipalities due to difficulty in coordination. During the collection of the data, many hospitals declined to participate in our survey. The loss of data may lead to bias. In the meantime, the grouping of the patients transferred to different hospitals outside Sichuan province based on the distance 
between two places is just very general and may not be very accurate. A comparison between the hospitals in Chongqing and those in the other places is needed to ascertain the situation within different places.

\section{Acknowledgements}

This study was supported by the grants from the Scientific and Technologic Project of Chongqing, China (No. CSTC, 2008AA0011) and National High-tech R\&D Program (863 Program) of China (No. 2008AA022501). The authors wish to thank all the participants in the study for their enthusiastic collaboration.

\section{Conflict of Interest}

There is no any conflict of interests to disclose.

\section{References}

[1] Chan, E.Y. (2008) The Untold Stories of the Sichuan Earthquake. The Lancet, 372, 359-362. http://dx.doi.org/10.1016/S0140-6736(08)61141-1

[2] Tang, Y.L., Zhu, G.Q., Zhou, H., Zheng, M., Tang, X.F., Wang, X.Y. and Liang, X.H. (2009) Analysis of 46 Maxillofacial Fracture Victims in the 2008 Wenchuan, China Earthquake. Oral Surgery, Oral Medicine, Oral Pathology, Oral Radiology, and Endodontology, 108, 673-678. http://dx.doi.org/10.1016/j.tripleo.2009.05.031

[3] Shi, Y.K., Wang, L.L., Lin, Y.D., Pei, F.X. and Kang, Y.M. (2010) Challenges for Rear Hospital Care of Wenchuan Earthquake Casualties: Experience from West China Hospital. Chinese Journal of Traumatology, 13, 131-136.

[4] Ukai, T. (1997) The Great Hanshin-Awaji Earthquake and the Problems with Emergency Medical Care. Renal Failure, 19, 633-645. http://dx.doi.org/10.3109/08860229709109029

[5] Tanaka, H., Oda, J., Iwai, A., Kuwagata, Y., Matsuoka, T., Takaoka, M., Kishi, M., Morimoto, F., Ishikawa, K., Mizushima, Y., et al. (1999) Morbidity and Mortality of Hospitalized Patients after the 1995 Hanshin-Awaji Earthquake. American Journal of Emergency Medicine, 17, 186-191. http://dx.doi.org/10.1016/S0735-6757(99)90059-1

[6] Yoshikawa, J. (1995) How to Solve Hospital Operating Problems Based on the Experience of the Hanshin Earthquake? Journal of Cardiology, 25, 337-339.

[7] Tanaka, K. (1996) The Kobe Earthquake: The System Response. A Disaster Report from Japan. European Journal of Emergency Medicine, 3, 263-269. http://dx.doi.org/10.1097/00063110-199612000-00009

[8] Papadopoulos, I.N., Kanakaris, N., Triantafillidis, A., Stefanakos, J., Kainourgios, A. and Leukidis, C. (2004) Autopsy Findings from 111 Deaths in the 1999 Athens Earthquake as a Basis for Auditing the Emergency Response. British Journal of Surgery, 91, 1633-1640. http://dx.doi.org/10.1002/bjs.4752

[9] Spencer, H.C., Campbell, C.C., Romero, A., Zeissig, O., Feldman, R.A., Boostrom, E.R. and Long, E.C. (1977) Disease-Surveillance and Decision-Making after the 1976 Guatemala Earthquake. The Lancet, 2, 181-184. http://dx.doi.org/10.1016/S0140-6736(77)90193-3

[10] Nie, H., Tang, S.Y., Lau, W.B., Zhang, J.C., Jiang, Y.W., Lopez, B.L., Ma, X.L., Cao, Y. and Christopher, T.A. (2010) Triage during the Week of the Sichuan Earthquake: A Review of Utilized Patient Triage, Care, and Disposition Procedures. Injury, 41, 866-871.

[11] Leonard, R.B., Stringer, L.W. and Alson, R. (1995) Patient-Data Collection System Used during Medical Operations after the 1994 San Fernando Valley-Northridge Earthquake. Prehospital and Disaster Medicine, 10, 178-183.

[12] Wen, Y.-S., Hsu, C.-P., Lin, T.-C., Yang, D.-Y. and Wu, T.-C. (2000) Chest Injuries Transferred to Trauma Centers after the 1999 Taiwan Earthquake. American Journal of Emergency Medicine, 18, 825-827. http://dx.doi.org/10.1053/ajem.2000.18132

[13] Rathore, F.A., Farooq, F., Muzammil, S., New, P.W., Ahmad, N. and Haig, A.J. (2008) Spinal Cord Injury Management and Rehabilitation: Highlights and Shortcomings from the 2005 Earthquake in Pakistan. Archives of Physical Medicine and Rehabilitation, 89, 579-585. http://dx.doi.org/10.1016/j.apmr.2007.09.027

[14] Qiu, J., Liu, G.D., Wang, S.X., Zhang, X.Z., Zhang, L., Li, Y., Yuan, D.F., Yang, Z.H. and Zhou, J.H. (2010) Analysis of Injuries and Treatment of 3401 Inpatients in 2008 Wenchuan Earthquake: Based on Chinese Trauma Databank. Chinese Journal of Traumatology, 13, 297-303.

[15] Dow, A.A., Clark, W.E., Farmer, J.C., Nolan, J.P. and Baskett, P.J. (1991) Disaster Management Organizations and Academic Perspective. Critical Care Clinics, 7, 257-270.

[16] Tanaka, H., Iwai, A., Oda, J., Kuwagata, Y., Matsuoka, T., Shimazu, T. and Yoshioka, T. (1998) Overview of Evacuation and Transport of Patients Following the 1995 Hanshin-Awaji Earthquake. The Journal of Emergency Medicine, 16, 
439-444. http://dx.doi.org/10.1016/S0736-4679(98)00014-6

[17] Jia, L., Li, G.P., You, C., Li, H., Huang, S.Q., Yang, C.H., Xiong, H. and Zeng, Y.J. (2010) The Epidemiology and Clinical Management of Craniocerebral Injury Caused by the Sichuan Earthquake. Neurology India, 58, 85-89. http://dx.doi.org/10.4103/0028-3886.60406

[18] Flaz, F., Hatipoglu, S. and Aydin, H. (2008) Effectiveness of Psychoeducation Intervention on Post-Traumatic Stress Disorder and Coping Styles of Earthquake Survivors. Journal of Clinical Nursing, 17, 677-687. http://dx.doi.org/10.1111/j.1365-2702.2007.02047.x

[19] Benson, M., Koenig, K.L. and Schultz, C.H. (1996) Disaster Triage: Start, then Save: A New Method of Dynamic Triage for Victims of a Catastrophic Earthquake. Prehospital and Disaster Medicine, 11, 117-124.

[20] Taylor, M. (2004) Surveying the Damage. Hurricane Charley Wreaks Havoc on Florida Hospitals. Modern Healthcare, 34, 28.

[21] Staver, S. (1979) Hurricane Causes Major Damage to Hospitals on Gulf Coast. American Medical News, $22,3$.

[22] Siddiqi, K. (2006) The Pakistan Earthquake: A Personal Experience. The Lancet, 367, 986. http://dx.doi.org/10.1016/S0140-6736(06)68423-7

[23] Sheng, Z.Y. (1987) Medical Support in the Tangshan Earthquake: A Review of the Management of Mass Casualties and Certain Major Injuries. The Journal of Trauma, 27, 1130-1135. http://dx.doi.org/10.1097/00005373-198710000-00007

[24] Tahmasebi, M.N., Kiani, K., Mazlouman, S.J., Taheri, A., Kamrani, R.S., Panjavi, B. and Harandi, B.A. (2005) Musculoskeletal Injuries Associated with Earthquake. A Report of Injuries of Iran's 26 December 2003 Bam Earthquake Casualties Managed in Tertiary Referral Centers. Injury, 36, 27-32.

[25] Yang, C., Wang, H.-Y., Zhong, H.-J., Zhou, L., Jiang, D.-M., Du, D.-Y., Hu, P. and Jiang, J.-X. (2009) The Epidemiological Analyses of Trauma Patients in Chongqing Teaching Hospitals Following the Wenchuan Earthquake. Injury, 40, 488-492. http://dx.doi.org/10.1016/j.injury.2009.01.102

[26] Walker, G.J. and Blood, C.G. (1999) The Patient Flow of Marine Disease and Non-battle Injury Conditions within a Multi-Echelon System of Care. Journal of Military Medicine, 164, 731-736.

[27] Sternberg, E., Lee, G.C. and Huard, D. (2004) Counting Crises: US Hospital Evacuations, 1971-1999. Prehospital and Disaster Medicine, 19, 150-157.

[28] Schultz, C.H., Koenig, K.L. and Lewis, R.J. (2003) Implications of Hospital Evacuation after the Northridge, California, Earthquake. The New England Journal of Medicine, 348, 1349-1355. http://dx.doi.org/10.1056/NEJMsa021807

[29] Senkowski, C.K. and McKenney, M.G. (1999) Trauma Scoring Systems: A Review. Journal of the American College of Surgeons, 189, 491-503. http://dx.doi.org/10.1016/S1072-7515(99)00190-8

[30] Harwood, P.J., Giannoudis, P.V., Probst, C., Van Griensven, M., Krettek, C. and Pape, H.C. (2006) Which AIS Based Scoring System Is the Best Predictor of Outcome in Orthopaedic Blunt Trauma Patients? The Journal of Trauma, 60, 334-340. http://dx.doi.org/10.1097/01.ta.0000197148.86271.13

[31] Sutherland, A.G., Johnston, A.T. and Hutchison, J.D. (2006) The New Injury Severity Score: Better Prediction of Functional Recovery after Musculoskeletal Injury. Value in Health, 9, 24-27. http://dx.doi.org/10.1111/j.1524-4733.2006.00077.x

[32] Sakas, D.E., Singounas, E.G. and Karvounis, P.C. (1989) Spontaneous Intracerebral Haematomas: Surgical versus Conservative Treatment Based on Glascow Coma Scale Score and Computer Tomography Data. Journal of Neurosurgical Sciences, 33, 165-172.

[33] Maruo, S. and Matumoto, M. (1996) Spinal Fractures Resulting from the 1995 Great Hanshin Earthquake of the KobeOsaka Area of Japan. Spinal Cord, 34, 382-386. http://dx.doi.org/10.1038/sc.1996.69

[34] Noji, E.K., Kelen, G.D., Armenian, H.K., Oganessian, A., Jones, N.P. and Sivertson, K.T. (1990) The 1988 Earthquake in Soviet Armenia: A Case Study. Annals of Emergency Medicine, 19, 891-897. http://dx.doi.org/10.1016/S0196-0644(05)81563-X

[35] Zhang, L., Fu, P., Wang, L., Cai, G., Chen, D., Guo, D., Sun, X., Chen, F., Bi, W., Zeng, X., et al. (2010) The Clinical Features and Outcome of Crush Patients with Acute Kidney Injury after the Wenchuan Earthquake: Differences between Elderly and Younger Adults. Injury, 43, 1470-1475.

[36] Gonzalez, D. (2005) Crush Syndrome. Critical Care Medicine, 33, S34-S41. http://dx.doi.org/10.1097/01.CCM.0000151065.13564.6F

[37] Shimazu, T., Yoshioka, T., Nakata, Y., Ishikawa, K., Mizushima, Y., Morimoto, F., Kishi, M., Takaoka, M., Tanaka, H., Iwai, A., et al. (1997) Fluid Resuscitation and Systemic Complications in Crush Syndrome: 14 Hanshin-Awaji Earthquake Patients. The Journal of Trauma, 42, 641-646. 
http://dx.doi.org/10.1097/00005373-199704000-00010

[38] Li, W., Qian, J., Liu, X., Zhang, Q., Wang, L., Chen, D. and Lin, Z. (2009) Management of Severe Crush Injury in a Front-Line Tent ICU after 2008 Wenchuan Earthquake in China: An Experience with 32 Cases. Critical Care, 13, R178. http://dx.doi.org/10.1186/cc8160

[39] Zhong, G., Pei, F., Zhong, Z., Huang, F., Song, Y. and Yang, T. (2010) Influence Factors for Limb Salvage of Bone Fracture Patients with Hyperpotassemia Caused by Earthquake. Yi Xue Ban Journal of Central South University, 35, 182-184.

[40] Liu, L., Tang, X., Pei, F.X., Tu, C.Q., Song, Y.M., Huang, F.G., Yang, T.F., Wang, G.L., Fang, Y., Zhang, H., et al. (2010) Treatment for 332 Cases of Lower Leg Fracture in "5.12" Wenchuan Earthquake. Chinese Journal of Traumatology, 13, 10-14.

[41] Yang, Y.F., Ye, Y.L., Li, T., Liu, X.X. and Yuan, P. (2010) Mental Health Status among Middle School Students in Wenchuan Earthquake Region. Chinese Journal of Preventive Medicine, 44, 134-139.

[42] Figueroa, R.A., Marin, H. and Gonzalez, M. (2010) Psychological Support for Disaster Victims: An Evidence-Based Care Model. Revista médica de Chile, 138, 143-151.

[43] Shichida, H. (1996) Status and Problems Associated with Disaster-Related Psychiatric Care in Hokkaido-Experiences during the Earthquake of the Southwest Coast of Hokkaido. Psychiatria et Neurologia Japonica, 98, 793-798.

[44] Trichopoulos, D., Katsouyanni, K., Zavitsanos, X., Tzonou, A. and Dalla-Vorgia, P. (1983) Psychological Stress and Fatal Heart Attack: The Athens (1981) Earthquake Natural Experiment. The Lancet, 1, 441-444. http://dx.doi.org/10.1016/S0140-6736(83)91439-3

[45] Wang, H., Jin, H., Nunnink, S.E., Guo, W., Sun, J., Shi, J., Zhao, B., Bi, Y., Yan, T., Yu, H., et al. (2010) Identification of Post Traumatic Stress Disorder and Risk Factors in Military First Responders 6 Months after Wenchuan Earthquake in China. Journal of Affective Disorders, 130, 213-219.

[46] Shih, F.J., Liao, Y.C., Chan, S.M. and Gau, M.L. (2002) Taiwanese Nurses' Most Unforgettable Rescue Experiences in the Disaster Area after the 9-21 Earthquake in Taiwan. International Journal of Nursing Studies, 39, 195-206. http://dx.doi.org/10.1016/S0020-7489(01)00014-1

[47] Wang, J., Yang, F.D. and Sun, C.Y. (2008) The Analysis of Depression, Anxiety and Sleep Disorder in Earthquake-Related Injuries. Chinese Journal of Internal Medicine, 47, 721-722.

[48] Kun, P., Chen, X., Han, S., Gong, X., Chen, M., Zhang, W. and Yao, L. (2009) Prevalence of Post-Traumatic Stress Disorder in Sichuan Province, China after the 2008 Wenchuan Earthquake. Public Health, 123, 703-707. http://dx.doi.org/10.1016/j.puhe.2009.09.017

[49] Schultz, C.H., Koenig, K.L. and Noji, E.K. (1996) A Medical Disaster Response to Reduce Immediate Mortality after an Earthquake. The New England Journal of Medicine, 334, 438-444. http://dx.doi.org/10.1056/NEJM199602153340706

[50] Peleg, K., Reuveni, H. and Stein, M. (2002) Earthquake Disasters: Lessons to Be Learned. Israel Medical Association Journal, 4, 361-365.

[51] Saghafinia, M., Araghizade, H., Nafissi, N. and Asadollahi, R. (2007) Treatment Management in Disaster: A Review of the Bam Earthquake Experience. Prehospital and Disaster Medicine, 22, 517-521. 